This article has been accepted for publication in a future issue of this conference proceedings, but has not been fully edited. Content may change prior to final publication. Citation information: DOI:10.1109/UPEC50034.2021.9548254, 2021 56th International Universities Power Engineering Conference (UPEC).

\title{
Frequency Stability Considerations of Reciprocating Gas Engine Generators in Microgrids
}

\author{
Stephen Sommerville \\ Department of Electronic \& \\ Electrical Engineering \\ Brunel University \\ London, UK \\ stephen.sommerville@brunel. \\ ac.uk
}

\author{
Professor Gareth Taylor \\ Department of Electronic \& \\ Electrical Engineering \\ Brunel University \\ London, UK \\ gareth.taylor@brunel.ac.uk
}

\author{
Dr Maysam Abbod \\ Department of Electronic \& \\ Electrical Engineering Brunel \\ University \\ London, UK \\ maysam.abbod@brunel.ac.uk
}

\begin{abstract}
This paper considers the suitability of the standard DEGOV diesel generator governor model for use with reciprocating gas engine generators within microgrids, due to their reduced step loading capability. The paper found that use of the standard DEGOV model would significantly overestimate the gas engines capability to accept step load, and an alternate model was developed to use a gain scheduling variable gain factor within the controller, based on the generators existing loading. This model was found to be effective, but it was identified that the varying values of gain could lead to controller instability and tuning problems, and further investigation work in this area is necessary.
\end{abstract}

Keywords-Microgrid, Governor, DEGOV, Gas Engine, Diesel Engine, Generator, ISO 8528-5.

\section{INTRODUCTION}

Power System Stability is a key area of interest for system designers and the system operator, due to the increasing diversity of generation sources and penetration of renewable generation. Work by the IEEE PES and CIGRE have resulted in a number of guidance reports on governing modelling for stability simulations [1] \& [2], however these reports tend to favour large interconnected power systems, and historically less attention has been given to Microgrids. Recent work by the IEEE has shown that microgrid system stability considerations remain a very active research topic [1].

Due to increasing environmental pressures and awareness many Microgrid operators have started moving away from traditional diesel generators and are trying to develop microgrids based on a mixture of reciprocating gas engine generators, solar PV and wind power. Whilst renewable technologies are still actively researched, many operators consider the use reciprocating gas engines, due to their dispatchability, availability, high efficiencies, lower emissions, inertia, and greater availability of fuel types for combustion. What is often overlooked however, is that reciprocating gas engines have a much lower ability to accept and reject step load changes due to their mechanical engine limits [4], [5], and have much reduced wider frequency deviation limits given in ISO 8528-5 [6].

Within this paper the suitability of reciprocating gas engine generators as the primary means of providing frequency stability, will be examined in contrast to traditional reciprocating diesel engine generators. This will be carried out by considering the suitability of the standard IEEE DEGOV/DEGOV1 governor model used in most power system simulation studies against a new customized gas engine governor model, referred to as GEGOV. The analysis is carried out using a simplified model of a power system frequency response through implementation in
MATLAB/Simulink of the swing equation in a feedback loop with the governor output.

\section{MICROGRID STABILITY}

\section{A. Stability Classification}

Power system stability problems have been conventionally split into three main areas known as frequency stability, voltage stability and rotor angle stability, which are then further sub-divided into different areas [9]. Recent developments in renewable technologies have led to wider definition of stability classifications to include systems with high penetration of renewable technologies [8] and for the specific requirements of microgrids [3]. A summary of the key classifications of microgrids can be seen below in Figure 1.

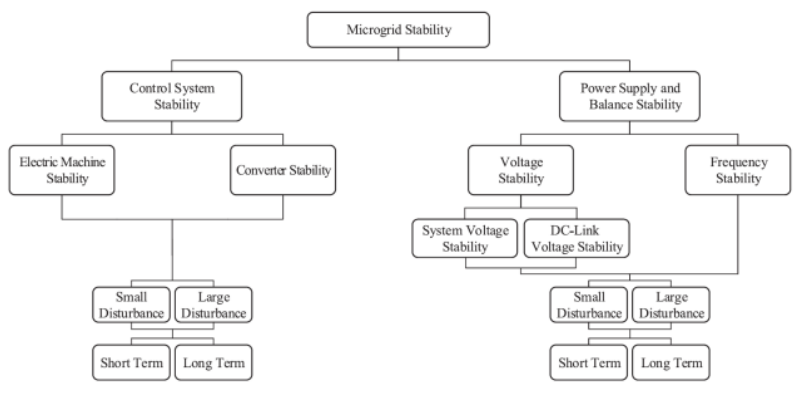

Figure 1. Microgrid Stability Definitions

Conventional microgrids have been usually based around either diesel generators, or small gas turbines that provide main power and primary frequency control, however, in recent years this has changed due to the increasing penetration of inverter-based generation and prevalence of reciprocating gas engines, and microgrid stability remains an active area of interest and research, as they face additional concerns when compared to traditional stability analysis [3], [9] \& [10].

\section{B. Frequency Stability}

Within Microgrids the problem of frequency stability remains acute, and system collapse due to mismatches between available generation and load is a key concern due to the low inertia available in the system and the potential rapid frequency collapse. Even relatively modest changes in loads can lead to large frequency and voltage deviations in the electrical system, and conventional control systems may not be sufficient to manage the rapid fluctuations. A typical system response can be shown in Figure 2 [1].

In classical power system stability, the system frequency response and rate of change of frequency can be determined through solving of the swing equation as shown below in Equation 1, and in alternative format in Equation 2. 
This article has been accepted for publication in a future issue of this conference proceedings, but has not been fully edited. Content may change prior to final publication. Citation information: DOI:10.1109/UPEC50034.2021.9548254, 2021 56th International Universities Power Engineering Conference (UPEC).

$$
\begin{gathered}
\frac{2 H}{\omega_{s}} \frac{d^{2} \delta}{d t^{2}}=P_{m}-P_{e}=P_{a} \\
\frac{d f}{d t}=\frac{P_{\text {in }}-P_{\text {out }}}{2 S H} f
\end{gathered}
$$

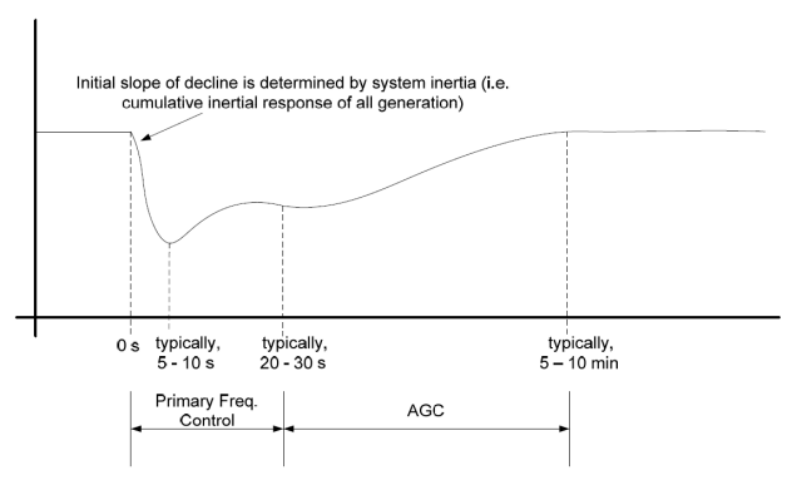

Figure 2. Typical Frequency Response

Most modern computer simulation packages use repeated iterations of the swing equation to solve frequency stability problems [9]. When this is coupled with the generator governor control the system the instantaneous power mismatch and the relationship between system inertia and frequency and generator power output can be resolved to find the new operating point for generators in the system.

\section{DIESEl ENGINE \& GAS ENGINE COMPARISON}

\section{A. Combustion Technologies}

Reciprocating gas engines and diesel engines are very similar in design, and while they are based on the same principles, there are a number of important differences; conventional diesel engines are fed with a constant pressure of diesel that is pumped to the injectors, whilst gas engines are fed with a gas that can vary in pressure and in methane/oxygen content. This leads to a more complex set of parameters for consideration in a gas engine and different response characteristic [4], [7] \& [8]. Typical parameters that need to be considered in the performance of reciprocating generator set are:

- Fuel Type - Liquid Diesel vs Gas Type (i.e. Natural Gas, Landfill Gas, Sewage Gas etc.)

- Calibration \& sizing of throttle body for balancing Air \& Fuel.

- Air \& Fuel Ratio Requirements.

- Throttle Control Geometry.

- Gas Pressure.

- Available gas Volume.

- Methane / Oxygen Content.

\section{B. Load Step Capability}

The electrical performance of reciprocating diesel and gas engine sets is defined within the ISO 3046-4 [13] and ISO 8528-5 [6] standard. In particular, ISO 8528-5 defines the ability of a reciprocating engine generator sets load acceptance capability, where the performance is given in terms of an individual machines frequency drop for a given load step.

A generators load step capability is defined in relation to the generators Break Mean Effective Pressure (BMEP), from Figure 6 in ISO 8528-5. Considering a single generator, the following general process is followed. Firstly, the block load step must be expressed as a percentage of the generator rating (i.e. $500 \mathrm{~kW}$ load step on a $1000 \mathrm{~kW}$ engine is a $50 \%$ load step). Secondly, the generator BMEP is identified from the generator datasheet. Thirdly, ISO $8528-5$ is consulted and if the percentage of the load step is below the first load step curve, then the generator can take the load as a single step.

If the load step is above the first curve, but below the second curve, it will require two load steps; if the load step percentage is above the first two curves, but below the third, then it will take three load steps and so on. A copy of the ISO 8528-5 step loading limits is shown below in Figure 3.

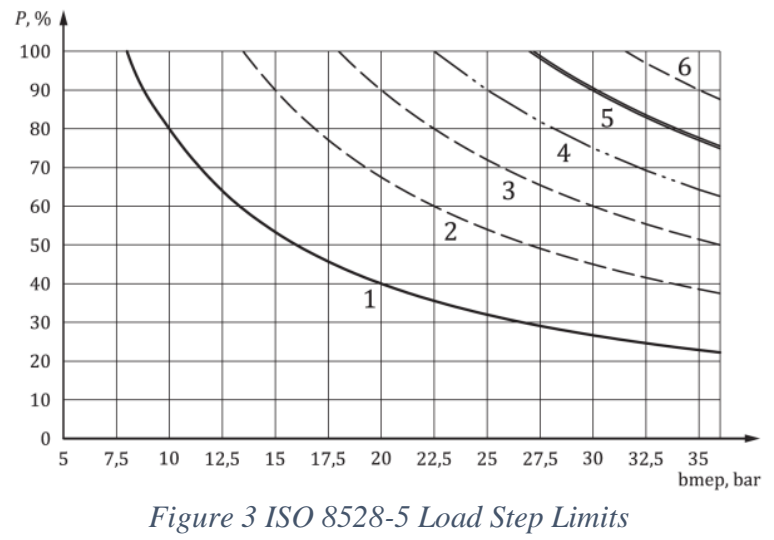

For example. A machine with a 20bar BMEP, could take up to a $40 \%$ load step in a single step, while a $50 \%$ load step would need to be split into two smaller steps and a $100 \%$ load step would require 4 steps. Similarly, a machine with a $30 \mathrm{bar}$ BMEP, would require 2 steps to take $40 \%$ load, 3 steps to take $50 \%$ loads and exactly 5 steps to take $100 \%$ load.

It is of course noted that the maximum load step any generator can take will be its maximum power rating + overload margin. Thus, even a low 7.5 bar BMEP machine, would still only be able to take a $100 \%$ load step. The load step limitations given in the load step diagram are based on the expected frequency and voltage deviation that the machine is permitted according to its performance class of G1, G2, G3 or G4. Typically, G1 performance class machines are intended for light use and parallel operation with a grid, whilst G2 and G3 performance class are heavier duty and have an improved capability to manage step loads.

Generator sets classified as type G4 are subject to specific performance requirements and are referred to as an Agreement between the Manufacturer and Customer (AMC), based on the machine design, ambient conditions, and available fuel gas. These limits are detailed in Table 1, of ISO 8528-5, and are presented in a simplified format.

From Figure 3 and Table 1 we could see that a diesel generator, rated $1000 \mathrm{~kW}$, with a BMEP of 20 bar, taking a load step of $40 \%$ would be allowed a frequency deviation of $10 \%$ and a 5 s recovery time if it was rated for $\mathrm{G} 2$ performance class; but a 7\% frequency deviation and a $3 \mathrm{~s}$ recovery time if it was rated for $\mathrm{G} 3$ performance class. The equivalent gas engine would be allowed a $20 \%$ frequency deviation if it was a G2 performance class, and a $15 \%$ frequency deviation if it was rated for $\mathrm{G} 3$ performance class. 
This article has been accepted for publication in a future issue of this conference proceedings, but has not been fully edited. Content may change prior to final publication. Citation information: DOI:10.1109/UPEC50034.2021.9548254, 2021 56th International Universities Power Engineering Conference (UPEC).

Table 1 ISO 8528-5 Performance Limits

\begin{tabular}{|c|c|c|c|c|c|}
\hline \multirow{3}{*}{\multicolumn{2}{|c|}{ Parameter }} & \multicolumn{4}{|c|}{ Operating limit values } \\
\hline & & \multicolumn{4}{|c|}{ Performance class } \\
\hline & & G1 & G2 & G3 & G4 \\
\hline \multicolumn{2}{|c|}{$\begin{array}{c}\text { Steady-state frequency } \\
\text { band }\end{array}$} & $2.50 \%$ & $1.50 \%$ & $0.50 \%$ & AMC \\
\hline \multirow{3}{*}{$\begin{array}{l}\text { Transient } \\
\text { frequency } \\
\text { difference } \\
\text { from } \\
\text { initial } \\
\text { frequency }\end{array}$} & $\begin{array}{c}100 \% \\
\text { sudden } \\
\text { power } \\
\text { decrease }\end{array}$ & $\leq 18 \%$ & $\leq 12 \%$ & $\leq 10 \%$ & \multirow{3}{*}{ AMC } \\
\hline & $\begin{array}{l}\text { Sudden } \\
\text { power } \\
\text { increase } \\
\text { (Diesel) }\end{array}$ & $\leq 15 \%$ & $\leq 10 \%$ & $\leq 7 \%$ & \\
\hline & $\begin{array}{l}\text { Sudden } \\
\text { power } \\
\text { increase } \\
\text { (Gas) }\end{array}$ & $\leq 25 \%$ & $\leq 20 \%$ & $\leq 15 \%$ & \\
\hline \multicolumn{2}{|c|}{ Frequency recovery time } & $10 \mathrm{~s}$ & $5 \mathrm{~s}$ & $3 \mathrm{~s}$ & AMC \\
\hline
\end{tabular}

\section{Load Step Capability Diagrams}

Due to the differing performance characteristics of gas engines [4] \& [11], most manufacturers define the load step capability of their machines through the use of a load step capability diagram. A typical example of this is shown below taken from a position paper produced by the International Council on Combustion Engines (CIMAC), on the transient response of gas engines [4]. This paper shows a comparison between diesel engines and gas engines and typical load step response capability, which is reproduced in Figure 4.

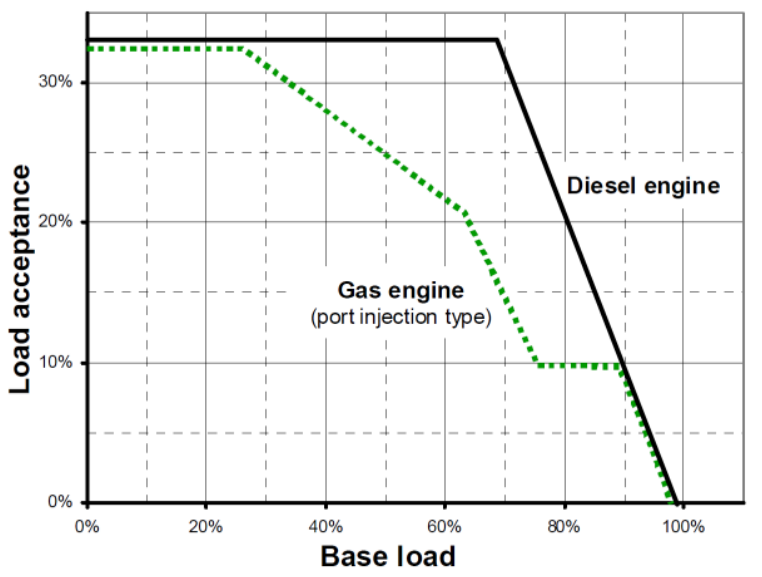

Figure 4 Load Step Capability Comparison

The graph for the diesel engine shows a fixed load acceptance value of $33 \%$ up to a base load of $67 \%$, at which point the load acceptance drops off linearly with the base load, such that the total load does not exceed $100 \%$. It can be seen that for the Gas Engine, the situation is more complex and the load acceptance capability is non-linear, and consists of a number of different Load Acceptance $(L A)$ capability values, depending on the Base Load $(B L)$. The above response can be represented by a set of discrete piecewise defined linear functions.

Equations 3 represent the response for the gas engine shown in Figure 4 but could be easily adapted or expanded to represent any load capability diagram into a set of similar linear equation. Where a flat response is present on the Gas
Engine capability diagram the slope is represented as a simple constant value.

$$
\left.L A=\begin{array}{cc}
0.333 & (0<B L<0.28) \\
0.415-0.332 B L & (0.28 \leq B L<0.63) \\
0.725-0.833 B L & (0.63 \leq B L<0.75) \\
0.1 & (0.75 \leq B L<0.9) \\
1-B L & (0.9 \leq B L<1.0)
\end{array}\right)
$$

\section{DEGOV / DEGOV1 GOVERNOR MODEL}

\section{A. History}

The DEGOV and DEGOV1 governor models have been used as a standard modelling approach for diesel engine governors for a number of years. These are based on an original model developed by PTI/Siemens for PSS/E with input from Woodward, [10] \& [11]. These models have been implemented as a standard model available in many power system simulation software packages and have been used on many historic projects [16] \& [17], and are referenced in a number of the IEEE and NERC guidelines [1] \& [13]. It is noted that the DEGOV and DEGOV1 models are virtually identical, with the DEGOV1 model including an extra feedback loop to allow droop control.

A significant amount of research work has been carried out into developing accurate governor models for gas, steam and hydro turbines [1] \& [2]; however it was identified from a literature research that only limited development work has been carried out on DEGOV / DEGOV1 governor models for reciprocating gas engines.

\section{B. Governor Model}

The DEGOV1 model used in most power system studies, is a generic model that allows operation of the engine in both isochronous and a droop control model, and is based on a PID type configuration, containing 8 differential equations and 2 algebraic states, in addition a transport delay is included to allow for the engine time [10], [19] \& [20]. A standard implementation of the DEGOV governor model can be seen in Figure 5.

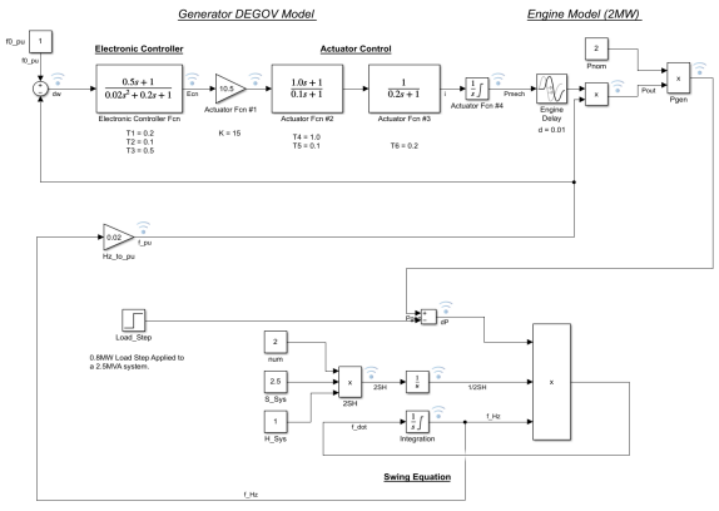

Figure 5. Simulink Model of Governor \& Swing Equation 
This article has been accepted for publication in a future issue of this conference proceedings, but has not been fully edited. Content may change prior to final publication. Citation information: DOI:10.1109/UPEC50034.2021.9548254, 2021 56th International Universities Power Engineering Conference (UPEC).

\section{Governor Parameters}

The typical factor that affects load response of a reciprocating engine and the DEGOV model is the gate opening time, as this is responsible for delivering more fuel into the system. This means that modifying the gain $K$ or the two time constant T4 or T5 will alter the load step response of the generator [10], [19], [21] \& [22] and be used as the starting point for tuning. Setting the parameters of K, T4 \& T5 should be undertaken based on the engine parameters and its classification as $\mathrm{G} 1 / \mathrm{G} 2 / \mathrm{G} 3$ to determine its response to specific load steps and load rejection. Typical parameters commonly suggested for a DEGOV model are shown in Table 2.

\section{Table 2. Typical DEGOV Values}

\begin{tabular}{|l|l|c|c|}
\hline \multirow{2}{*}{ Name } & \multicolumn{3}{|c|}{ Typical DEGOV Parameters } \\
\cline { 2 - 4 } K & \multicolumn{1}{|c|}{ Description } & Value & Unit \\
\hline T4 & Actuator Gain & 15 & {$[\mathrm{pu} / \mathrm{pu}]$} \\
\hline T5 & Actuator first time constant & 0.1 & {$[\mathrm{~s}]$} \\
\hline T6 & Actuator second time constant & 0.2 & {$[\mathrm{~s}]$} \\
\hline TD & Combustion Delay & 0.01 & {$[\mathrm{~s}]$} \\
\hline TE & Time const. Power fdbk & 0.1 & {$[\mathrm{~s}]$} \\
\hline T1 & $\begin{array}{l}\text { Electric control box first time } \\
\text { constant }\end{array}$ & 0.2 & {$[\mathrm{~s}]$} \\
\hline T2 & $\begin{array}{l}\text { Electric control box second time } \\
\text { constant }\end{array}$ & 0.1 & {$[\mathrm{~s}]$} \\
\hline T3 & $\begin{array}{l}\text { Electric control box derivative } \\
\text { time constant }\end{array}$ & 0.5 & {$[\mathrm{~s}]$} \\
\hline Tmin & Min. Throttle & 0 & {$[\mathrm{pu}]$} \\
\hline Tmax & Max. Throttle & 1.1 & {$[\mathrm{pu}]$} \\
\hline
\end{tabular}

\section{MATLAB/SIMULINK MODEL}

\section{A. Base Model and Validation}

Initially a model of the DEGOV governor was created in MATLAB/Simulink, which was then coupled with a mathematical equivalent model of the swing equation shown in equation (2) to allow creation of a simple closed loop feedback system that considered the governor response to a changing frequency and power imbalance as well as the system inertia.

The generator response in isochronous mode is of key interest, and therefore the DEGOV1 variant with the droop control loop was omitted, and to further simplify the modelling it was assumed that a generator would be provided with an AVR, to hold the system voltage at approximately 1.0 $\mathrm{pu}$, and therefore this aspect of the generator control system was not modelled or considered in the analysis. The combined model of the DEGOV governor and system representation with the swing equation can be seen in Figure 6.

Several initial simulations were carried out using the test network in Simulink, to consider the response of the machine defined below, which were benchmarked against an equivalent model in DIgSILENT PowerFactory.

- Machine Rating 2 MW

- System Inertia 2.5 MVA

- System Inertia Constant of 1.0

- BMEP of 20 bar

- Load Step of 0.8 MW (40\% of machine rating)

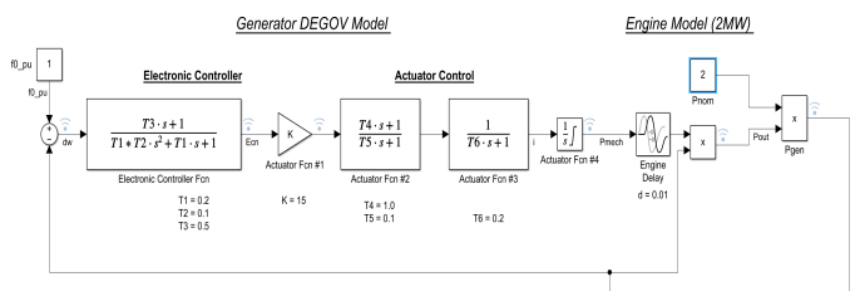

Figure 6. Typical DEGOV Model

Results from the test network detailed in Figure 6, and for the for the system parameters shown above were carried out, keeping all values constant and reducing the governor gain value to reach the expected frequency nadir for the different machine types given in Table 1 . The other time constants associated with the integral and derivative values are left as standard, although in practice these would be tuned to improve settling time and reduce overshoot of the governor. The following results were obtained, as summarized in Table 3 .

Table 3. Benchmark Results

\begin{tabular}{|l|c|c|c|c|}
\hline Base Load & $\begin{array}{l}\text { Expected } \\
\text { Frequency } \\
\text { Nadir }\end{array}$ & $\begin{array}{l}\text { Inertia } \\
\text { Constant } \\
\text { (H) }\end{array}$ & $\begin{array}{l}\text { Gain } \\
\text { Value } \\
\text { (K) }\end{array}$ & $\begin{array}{l}\text { Frequency } \\
\text { Nadir } \\
\text { (DEGOV) }\end{array}$ \\
\hline G1 Diesel & $42.5 \mathrm{~Hz}$ & 1 & 2.5 & $42.6 \mathrm{~Hz}$ \\
\hline G1 Gas & $37.5 \mathrm{~Hz}$ & 1 & 1.2 & $37.6 \mathrm{~Hz}$ \\
\hline G2 Diesel & $45.0 \mathrm{~Hz}$ & 1 & 5 & $45.1 \mathrm{~Hz}$ \\
\hline G2 Gas & $40.0 \mathrm{~Hz}$ & 1 & 1.6 & $40.0 \mathrm{~Hz}$ \\
\hline G3 Diesel & $46.5 \mathrm{~Hz}$ & 1 & 10.1 & $46.5 \mathrm{~Hz}$ \\
\hline G3 Gas & $42.5 \mathrm{~Hz}$ & 1 & 2.4 & $42.5 \mathrm{~Hz}$ \\
\hline
\end{tabular}

\section{B. Preliminary Assessment}

From the above analysis, the following general conclusions are drawn. Firstly, the lower the expected frequency nadir, dictated by the ISO 8528-5 standard, the lower the gain factor needed. Secondly, the lower the machine inertia the greater the frequency nadir, and conversely the higher the machine inertia the smaller the frequency nadir. Thirdly, increasing the controller gain factor improves the response of the governor and limits the frequency nadir by increasing the generator power output at a faster rate, causing the generator to respond before the natural frequency nadir occurs. Fourthly, there is a direct relationship between the machine inertia constant and the controller gain, and low inertia drives require a higher gain to prevent the frequency nadir being reached. Fifthly, the engine delay $T_{d}$ difference between gas engine and diesel engine creates only a minimal difference in the frequency nadir. Sixthly, the lower the machine BMEP the higher the gain factor of the controller required and vice versa.

It can therefore be concluded that simple adoption of the standard values given in the DEGOV model is unlikely to be suitable and will give misleading results in power system stability studies for gas engines. As a minimum, the studies engineer must consider the machine classification, BMEP and inertia and then carry out a tuning exercise to obtain a typical response characteristic before beginning any stability studies. 


\section{PRoposed GAS ENGINE GOVERNOR}

\section{A. Outline}

As demonstrated in the previous section, it has been identified that a gas engine has a very different response characteristic to a diesel engine, and therefore some modifications of the standard DEGOV model area needed, which we shall call GEGOV. A key point that must be recognized at this stage, is that most governor models approximate the engine (or turbine), that has been simplified for the purposes of system stability analysis. Full governor models developed by manufacturers are typically far more complex but contain several elements that do not need to be fully represented for the purposes of stability analysis.

\section{B. Gain Scheduling}

The problem with the basic DEGOV model application to gas engines, is that the gas engine characteristic is non-linear, and therefore the governor gain $K$ will vary depending on the base load of the generator. Thus, the non-linearity of the loadstep capability curves discussed above are not fully represented. This can be managed through adjusting the governor gain for a non-linear system, with an approach that is known as gain scheduling. The concept of gain scheduling is a well-established concept for nonlinear systems and is discussed further in [10], [19] \& [23].

Implementing a gain scheduling system within Simulink can be done in a variety of different ways, but the most straightforward is to use a 1D-Lookup table, with the input based on the machine loading and the output is the required gain value $K$. An additional engine loading model is also included to determine the engine base load, calculated from the system output and a pre-set loading value, is also included as shown in Figure 7.

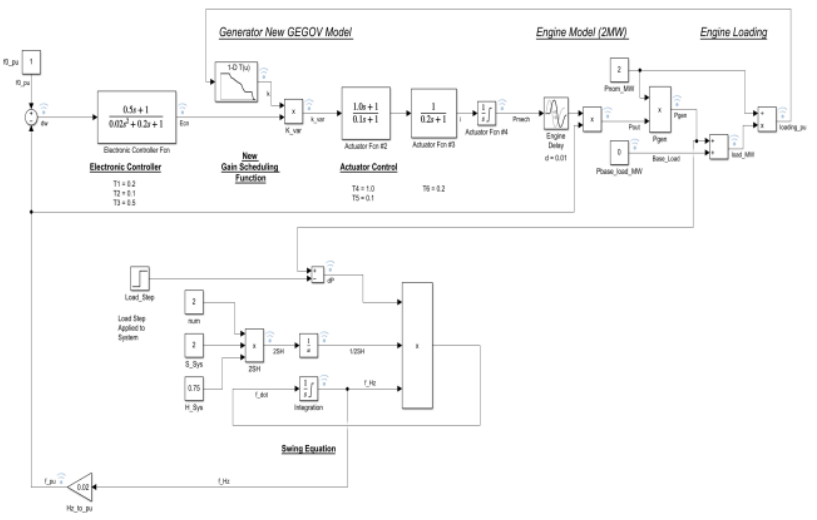

Figure 7. Modified DEGOV Model \& Swing Equation

In order to define the values in the 1D-lookup table, it is necessary to refer to the linear equations (3); a further simple calculation is required, to convert the known values of Base Load $(B L)$ and Load Acceptance value ( $L A)$, to a specific gain factor $K$. This can be determined, based on the assumption that gain is proportional to the load acceptance value ( $\mathrm{K} \alpha L A)$, and thus:

$$
K=c L A
$$

A tuning exercise is then carried out in a similar manner to that used in Section II, to determine the necessary constant $c$ for each of the stages in the equations given in (3). This is achieved by selecting known $L A$ and $B L$ values, which corresponds to a limit point of the step loading curve and then tuning the value of $K$ to get the expected response. Once these values are obtained, the value of $c$ can be derived and used to determine the other required gains to populate the lookup table as shown in Table 4.

\section{Table 4. Tests Loads for Lookup Table}

\begin{tabular}{|c|c|c|c|c|}
\hline $\begin{array}{c}\text { Base Load } \\
(\mathbf{B L})\end{array}$ & $\begin{array}{c}\text { Load } \\
\text { Acceptance } \\
(\mathbf{L A})\end{array}$ & $\begin{array}{c}\text { Constant } \\
\text { 'c' }\end{array}$ & Gain & $\begin{array}{c}\text { Test Load } \\
\text { (MW) }\end{array}$ \\
\hline $0 \%$ & $33.00 \%$ & 3.788 & 1.25004 & 0.660 \\
\hline $50 \%$ & $24.85 \%$ & 3.380 & 0.83993 & 0.497 \\
\hline $70 \%$ & $14.19 \%$ & 2.676 & 0.379724 & 0.284 \\
\hline $80 \%$ & $10.00 \%$ & 3.788 & 0.37880 & 0.200 \\
\hline $95 \%$ & $5.00 \%$ & 0.800 & 0.04000 & 0.050 \\
\hline
\end{tabular}

\section{Testing}

To demonstrate the system behaviour several simulation studies were carried out with different base loads set within the model. For each test scenario the frequency output at $2 \mathrm{~s}$ is recorded, as can be seen in Table 5 and an output plot of the frequency response shown as detailed in Figure 8. From the results several conclusions can be drawn.

Table 5 GEGOV Model Tests

\begin{tabular}{|c|c|l|l|c|}
\hline Base Load & $\begin{array}{l}\text { Calculated } \\
\text { Load Step } \\
\text { Limit }\end{array}$ & $\begin{array}{l}\text { Load } \\
\text { Step } \\
\text { Limit } \\
\text { Type }\end{array}$ & $\begin{array}{l}\text { Load } \\
\text { Applied } \\
\text { (MW) }\end{array}$ & $\begin{array}{l}\text { Frequency } \\
\text { Value at } \\
\text { 2 s. }\end{array}$ \\
\hline $0 \%(0 \mathrm{MW})$ & $33.3 \%$ & Constant & 0.667 & 42.3 \\
\hline $20 \%(0.4 \mathrm{MW})$ & $33.3 \%$ & Constant & 0.667 & 41.4 \\
\hline $30 \%(0.6 \mathrm{MW})$ & $31.5 \%$ & Linear & 0.667 & 40.7 \\
\hline $40 \%(0.8 \mathrm{MW})$ & $28.2 \%$ & Linear & 0.667 & 40.2 \\
\hline $50 \%(1.0 \mathrm{MW})$ & $24.8 \%$ & Linear & 0.667 & 39.3 \\
\hline $60 \%(1.2 \mathrm{MW})$ & $21.5 \%$ & Linear & 0.667 & 38.3 \\
\hline $70 \%(1.4 \mathrm{MW})$ & $14.2 \%$ & Linear & 0.667 & 37.8 \\
\hline
\end{tabular}

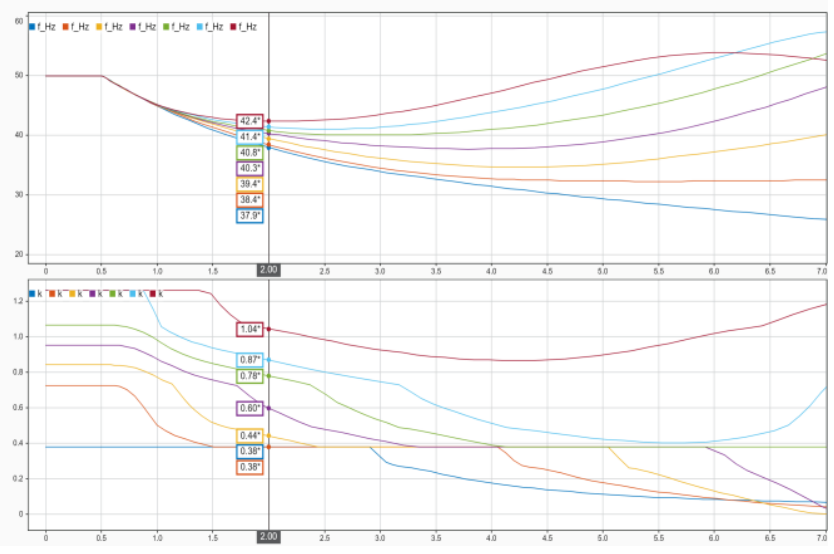

Figure 8. GEGOV Results

Firstly, the results of the GEGOV model differ significantly when compared to the base case results with the simple unmodified DEGOV model and a fixed gain. Secondly, the new governor model clearly shows an increased frequency deviation for the higher loadings, as was expected, leading to large deviations and slow recovery times for load 
This article has been accepted for publication in a future issue of this conference proceedings, but has not been fully edited. Content may change prior to final publication. Citation information: DOI:10.1109/UPEC50034.2021.9548254, 2021 56th International Universities Power Engineering Conference (UPEC).

steps where the existing base load is above $40 \%$. Thirdly, the gain factor $K$ can be seen varying, but more continuously than originally expected, and it is not clear without further testing if a gain should remain fixed for the whole load step duration, rather than actively varying during the response.

Overall, the results are generally in line with what was expected and demonstrate that the use of a simple governor model for a reciprocating gas engine may give overly optimistic results.

\section{CONCLUSIONS \& FURTHER WORK}

It has been demonstrated in this paper that the existing DEGOV model for reciprocating engines is suitable for diesel engines, provided that the machine classifications according to ISO 8528-5 and the relevant engine BMEP are understood. However, when considering gas engine generators, it was demonstrated that their complex load-step acceptance capability could not be suitably represented, and an alternative configuration is necessary.

The revised design, used a gain scheduling controller, based on the differing base loads to limit the gain of the controller in line with the generator step capability diagram. It was demonstrated that the new GEGOV model provided a more realistic response. It was noted from the results that use of a sample and hold element on the output of the lookup table, would prevent the gain varying during the load response and may be a more realistic approach.

Further work in this area would involve some liaison and field testing with gas engine generator set manufacturers to benchmark the governor parameters against a number of actual generating set data and to carry out some Hardware in the Loop field testing of the proposed governor model and parameters.

\section{REFERENCES}

[1] IEEE, "PES TR1: Dynamic Models for Turbine-Governors in Power System Studies," 2015.

[2] CIGRE, "Technical Brochure 238: Modeling of Gas Turbines and Steam Turbines in Combined Cycle Power Plants".

[3] "M. Farrokhabadi et al., "Microgrid Stability Definitions, Analysis, and Examples," in IEEE Transactions on Power Systems, vol. 35, no. 1, pp. 13-29, Jan. 2020, doi: 10.1109/TPWRS.2019.2925703.".

[4] "International Council on Combustion Engines, "Transient Response Behaviour of Gas Engines"," 2011.
[5] "A. Mondai, M. S. Illindala, A. A. Renjit and A. S. Khalsa,"Analysis of limiting bounds for stalling of natural gas genset in the CERTS microgrid test bed,"," 2014 IEEE International Conference on Power Electronics, Drives and Energy Systems (PEDES).

[6] ISO, "8528-5: Reciprocating internal combustion engine driven alternating current generating sets - Part 5: Generating sets".

[7] P. Kundur, Power System Stability and Control, McGraw Hill, 1994.

[8] IEEE, "PES TR-77: Definition and Classification of Power System Stability Revisited," 2020.

[9] ABB, "'Design and development of industrial microgrids", 2015, unpublished".

[10] "F. Conte, S. Massucco, F. Silvestro, F. Baccino and P. Serra, "Equivalent modelling of reciprocating engines generators for microgrid frequency response analysis"," IEEE Manchester PowerTech, Manchester, UK, 2017, pp. 1-6, 2017.

[11] Cummins, "Transient Performance of Generating Sets," 2019.

[12] Catepillar, "Applicattion and Installation Guide: Electric Power Applications, Generator \& Engine Sizing, unpublished," 2006.

[13] ISO, "3046-4: Reciprocating internal combustion engines Performance - Part 4: Speed governing".

[14] Woodward, "The Control of Prime Mover Speed - Mathematical Analysis, unpublished," 1981.

[15] Woodward, "Manual 26260: Governing Fundamentals and Power Management, unpublished".

[16] "K. E. Yeager and J. R. Willis, "Modeling of emergency diesel generators in an 800 Mega Watt nuclear power plant," in IEEE Transactions on Energy Conversion, vol. 8, no. 3, pp. 433-441, Sept. 1993," 1993.

[17] "L. N. Hannett, F. P. De Mlello, G. H. Tylinski and W. H. Becker, 'Validation of Nuclear Plant Auxiliary Power Supply by Test', in IEEE Transactions on Power Apparatus and Systems, vol. PAS-101, no. 9, pp. 3068-3074, Sept. 1982," 1982.

[18] NERC, "NERC Libraries of Standardized Powerflow Parameters and Standardized Dynamic Models, Version 1," NERC, 2015.

[19] "D. J. McGowan, D. J. Morrow and M. McArdle, 'A digital PID speed controller for a diesel generating set', 2003 IEEE Power Engineering Society General Meeting (IEEE Cat. No.03CH37491), 2003, pp. 14721477 Vol. 3,".

[20] "A. Nurkanović, A. Mešanović, M. Sperl, S. Albrecht, U. Münz, R Findeisen and M. Diehl, 'Optimization-Based Primary and Secondary Control of Microgrids', 2020, unpublished".

[21] "R. J. Best, J. M. Kennedy, D. J. Morrow and B. Fox, "Steady-State and Transient Performance of Biodiesel-Fueled Compression-Ignition-Based Electrical Generation," in IEEE Transactions on Sustainable Energy, vol. 2, no. 1, pp. 20-27, Jan. 2011," 2011.

[22] "D. J. McGowan, D. J. Morrow and B. Fox, "Multiple Input Governor Control for a Diesel Generating Set," in IEEE Transactions on Energy Conversion, vol. 23, no. 3, pp. 851-859, Sept. 2008,".

[23] "Rugh, W. J. and J. S. Shamma, 'Research on Gain Scheduling'. Automatica, 36, no. 10 (October 2000): 1401-1425.," 2000. 